\title{
Spatial Analytical Methods for Deriving a Historical Map of Physiological Equivalent Temperature of Hong Kong
}

\author{
Poh-Chin LAI ${ }^{\mathrm{a}}$, Crystal CY CHOI ${ }^{\mathrm{b} *}$, Paulina PY WONG ${ }^{\mathrm{a}}$, Thuan-Quoc THACH ${ }^{\mathrm{b}}$, Man Sing WONG ${ }^{\mathrm{c}}$, Wei CHENG ${ }^{\mathrm{a}}$, \\ Alexander KRÄMER ${ }^{\mathrm{d}}$, Chit-Ming WONG ${ }^{\mathrm{b}}$ \\ a Department of Geography, Faculty of Social Science, The University of Hong Kong, Pokfulam Road, Pokfulam, \\ Hong Kong \\ b School of Public Health, The University of Hong Kong, Pokfulam Road, Pokfulam, Hong Kong \\ c Department of Land Surveying and Geo-Informatics, The Hong Kong Polytechnic University, Hung Hom \\ Kowloon, Hong Kong \\ ${ }^{d}$ Department of Public Health Medicine, School of Public Health, University of Bielefeld, Bielefeld, Germany \\ * Corresponding author \\ (Postal address: School of Public Health, 5/F William MW Mong Block, 21 Sassoon Road, The University of \\ Hong Kong, Hong Kong. Tel: (+852) 2831 5053. Fax: (+852) 2855 9528. Email: crystalchoi220@ gmail.com)
}

Physiological Equivalent Temperature (PET) has been widely used as an indicator for impacts of climate change on thermal comfort of humans. The effects of thermal stress are often examined using longitudinal observational studies over many years. A major problem in retrospective versus prospective studies is that it is not feasible to go back in time to measure historical data not collected in the past. These data must be reconstructed for the baseline period to enable comparative analysis of change and its human impact. This paper describes a systematic method for constructing a PET map using spatial analytical procedures. The procedures involve estimating PET values (based on the RayMan model and four key parameters of temperature, relative humidity, wind velocity, and mean radiant temperature) at a spatially disaggregated level comprising of a grid of $100 \mathrm{~m} \times 100 \mathrm{~m}$ cells. The method can be applied to other geographic locations pending availability of basic meteorological and morphological data of the locations.

\section{Keywords}

Physiological Equivalent Temperature; PET; thermal comfort; spatial analysis; RayMan model; 
28 Hong Kong 
30 The world is warming up and there is increasing worldwide concern about the potential health

31 effects of climate change. Thermal stress, or the conditions of cold and hot temperatures beyond

32 the normal comfort range, has been the subject of much research due largely to more frequent

33 occurrences of heat waves and cold spells in high-latitude regions [1]. Human response to the

34 thermal environment is affected by local environmental variables (notably air temperature,

35 radiant temperature, humidity, and air movement) as well as the clothing worn and activity

36 engaged at the time $[2,3]$. An environment that is too hot, too cold, or just right can affect human

37 comfort and wellbeing because an individual must undergo thermoregulatory physiological

38 changes to adapt to the environment and maintain an internal body temperature of around $37{ }^{\circ} \mathrm{C}$

39 [4]. Long-term exposure to heat or cold can lead to serious health risks or death when the body

40 cannot sustain thermoregulatory function.

41 The Physiological Equivalent Temperature (PET) is a thermal index derived from the heat-

42 balance model of a human body [5]. It is a personal and geographic event that does not remain

43 constant over space and time. The RayMan model $[6,7]$ simulates short- and long-wave

44 radiation fluxes from a three-dimensional surrounding in simple and complex environments that

45 can be transferred into a synthetic parameter, also called the mean radiant temperature (Tmrt). By

46 supplying air temperature (Ta), relative humidity $(\mathrm{RH})$, wind velocity (WV) and Tmrt, PET

47 derived from the RayMan model is considered the same as that calculated using the PET Fortran

48 programme by Höppe [5, 8]. To facilitate studies of long-term health effects on thermal stress,

49 spatially defined data must be available to record signs of prolonged heat stress (as reflected

50 through time-series PET) and health responses of individuals (as measured by tracking subjects

51 over time). To create a map of PET which can account for thermal comfort conditions over a 
52 geographic extent, spatial analysis is essential to assemble individual PET values at respective

53 neighborhoods to create a generalized surface representation [9]. For example, a PET value can

54 be assigned to a neighborhood measuring $100 \mathrm{~m} \times 100 \mathrm{~m}$. A map of PET over a geographic

55 space will thus comprise of a collection of grid cells of a uniform size, each with a PET value.

56 To date, there have been numerous health effect studies on thermal stress but the majority has

57 focused on short-term exposure [10]. It is difficult to assess effects of long-term exposure to

58 thermal stress in a longitudinal cohort study partly because of confounding problems of

59 acclimatization and also because it is not feasible to obtain historical data on environmental

60 conditions to afford comparative analysis of changes. This paper presents a methodology to

61 derive historical maps of PET distribution through retrospective space-time analysis by

62 integrating time-sensitive environmental data and spatial analytical methods.

\section{2. Study Area and Method}

\section{2.1. Study Area}

65 The study area is the Hong Kong Special Administrative Region, which is situated east of the

66 Pearl River Estuary. Hong Kong measures 1,104 square kilometers in size and had a population

67 of over 7.2 million in mid-2014 [11]. A cohort of elderly people was first enrolled to the 18

68 elderly health centers of the Department of Health in 1998 - 2001 until the present time [12, 13].

69 The spatial distribution of this cohort of 66,820 persons $(61,588$ after data cleaning and taking

70 account of geocoding errors, missing data, and repeat/overlapping addresses) spans across Hong

71 Kong which dictates a spatial approach to health effect studies (Figure 1). 


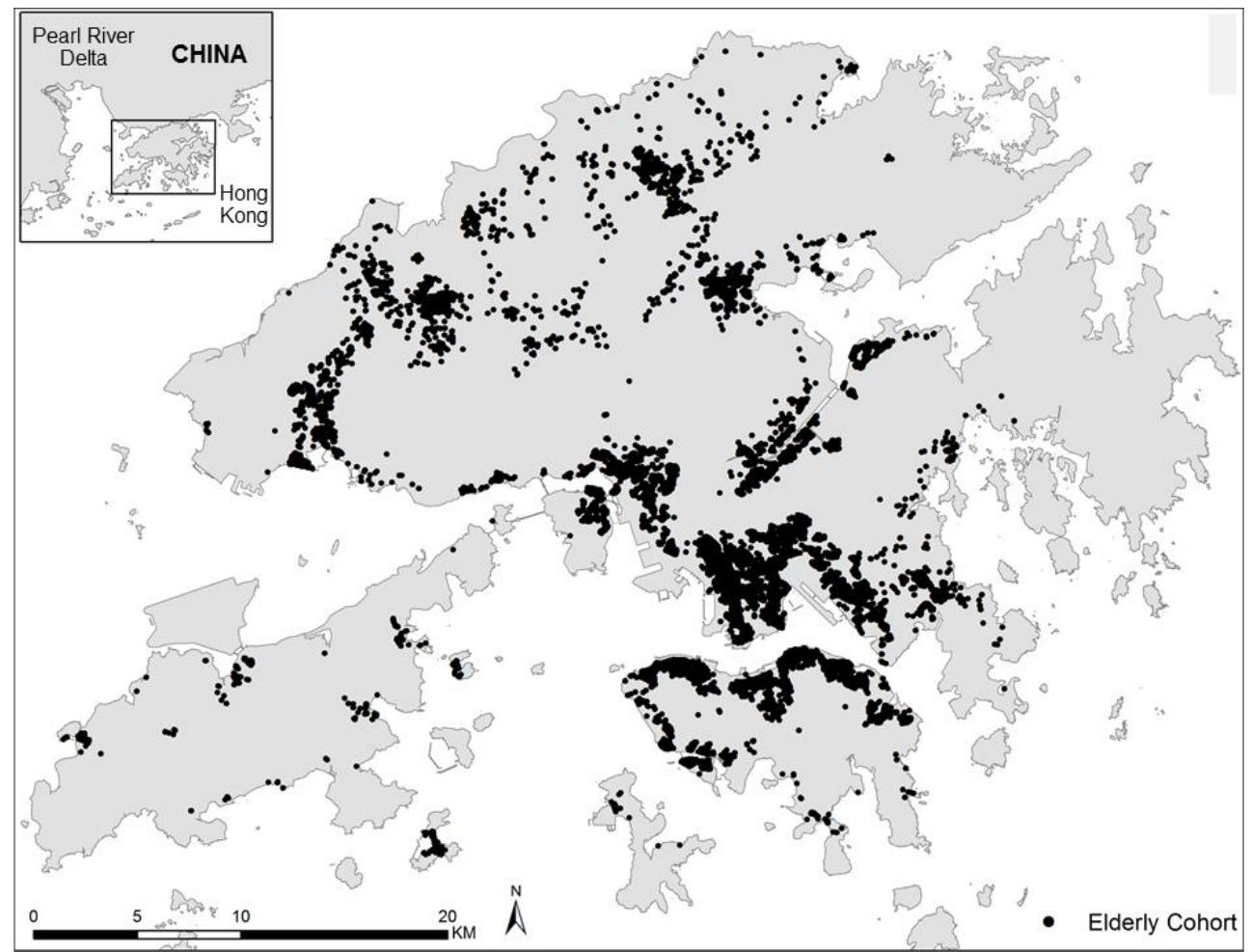

Figure 1: A map of Hong Kong showing the geographic distribution of the elderly cohort

74

75

76

77

78

79

80

81

82

83

84

\subsection{Environmental Data}

Various kinds of environmental data have been collected by the government of Hong Kong. The Hong Kong Observatory (HKO) has established meteorological monitoring stations to collect air temperature, relative humidity, wind, and cloud cover data for many years. The number of meteorological monitoring stations has increased from about 20 in early 1900s to over 40 in recent years. Each monitoring station has a coordinate to enable spatial interpolation of pointbased readings into a surface map of continuous measurements with varied degrees of spatial accuracy. WV data at reference heights are available from the Institute for the Environment at the Hong Kong University of Science and Technology (http://envf.ust.hk/). The simulated WV data were processed at high resolution using the MM5/CALMET system [14]. Similarly, the Survey and Mapping Office of the Lands Department has maintained a series of digital land records of 
85 Hong Kong at various map scales $(1: 1000,1: 5000,1: 10000$, and 1:20000) as well as digital

86 ortho-photographs (1:5000). These digital data include building footprints with years of

87 construction and height, contour elevation, road networks, coastlines, and other data.

88 Of particular interest to this study is the Urban Climate Analysis Map (UC-AnMap) of Hong

89 Kong from the Hong Kong Planning Department. The UC-AnMap was established in 2009 and

90 has a spatial resolution of $100 \mathrm{~m} \times 100 \mathrm{~m}$. It measures outdoor microclimatic conditions

91 considering the combined effects of buildings, open spaces, natural landscape, topography, and

92 wind conditions to imply the comfort sensation of people in outdoor spaces. This UC-AnMap

93 (Figure 2) conveys typical climate conditions in the hot and humid summer months of Hong

94 Kong (June, July and August 2008) and can serve as an "accepted" representation of summer

95 PET conditions in Hong Kong as verified from field measurements indicating a strong

96 relationship $\left(\mathrm{R}^{2} \approx 0.74\right)$ between the UC-AnMap classes and PET values [15]. 


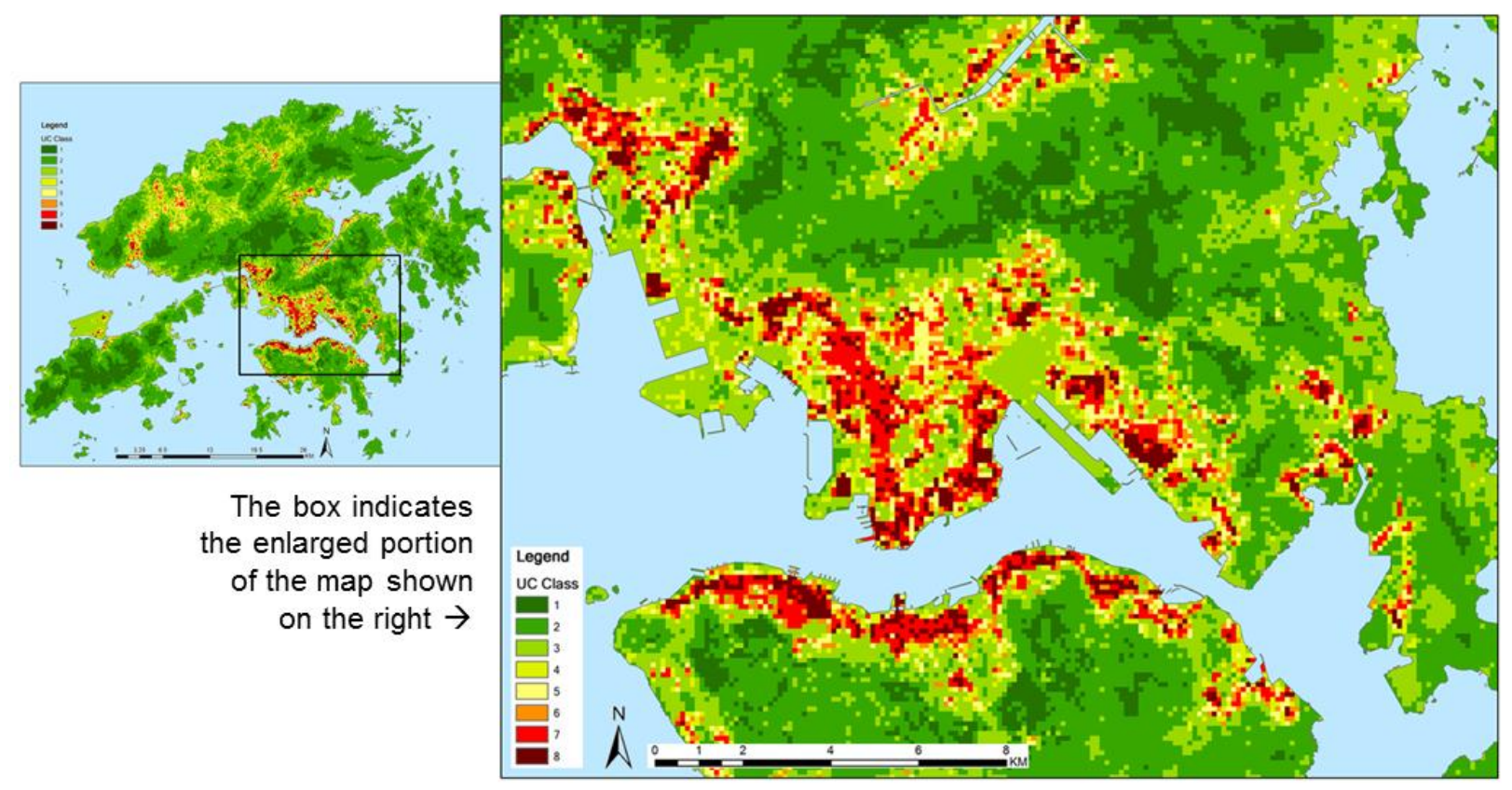

Figure 2: $\quad$ UC-AnMap showing climate zones of Hong Kong. Source: Hong Kong Planning Department.

98 Moreover, satellite images of Hong Kong can be sourced from international organizations. For

99 example, ASTER (Advanced Spaceborne Thermal Emission and Reflection Radiometer)

100 imagery is available from the U.S. National Aeronautics and Space Administration Terra satellite

101 since 2000 and current Landsat 5, 7, 8 satellite imageries can be acquired from the U.S.

102 Geological Survey.

\section{2.3. Computing Physiological Equivalent Temperature (PET)}

104 The RayMan Pro model [6, 7] was used to calculate PET values. Although the average height of 105 males in Hong Kong is 1.72 m [16], a recent study based on Chinese adults [2] on the effects of

106 height on mean skin temperature showed a difference of less than $0.2^{\circ} \mathrm{C}$ between men measuring

$107 \quad 1.72 \mathrm{~m}$ and $1.75 \mathrm{~m}$ in height. This slight difference in skin temperature should not pose 
108 significant impact on human thermoregulation. Therefore, this study adopted the default personal

109 values used in a recent study on thermal comfort in Hong Kong [3]: male, 35 years old, 1.75 m

110 in height, $75 \mathrm{~kg}$ in weight, indoor clothing ( 0.9 clo), light activity $(80 \mathrm{~W})$, and in a standing

111 position (Figure 3). Here, "0.9 clo" represents heat resistance of clothing in a typical indoor

112 setting and " $80 \mathrm{W"}$ represents a human body with work metabolism of light activity added to

113 basic metabolism. Locational and personal factors aside, it can be seen from Figure 3 that PET is

114 influenced by sun paths and local environmental conditions that include microclimate factors in a

115 complex urban structure. By supplying different values for Ta, RH, WV, and Tmrt while keeping

116 the rest of the parameters the same, PET values for all neighborhoods in Hong Kong can be

117 derived. The procedures to derive input parameters of Ta, RH, WV, and Tmrt by spatial analysis

118 method are described in the next section.

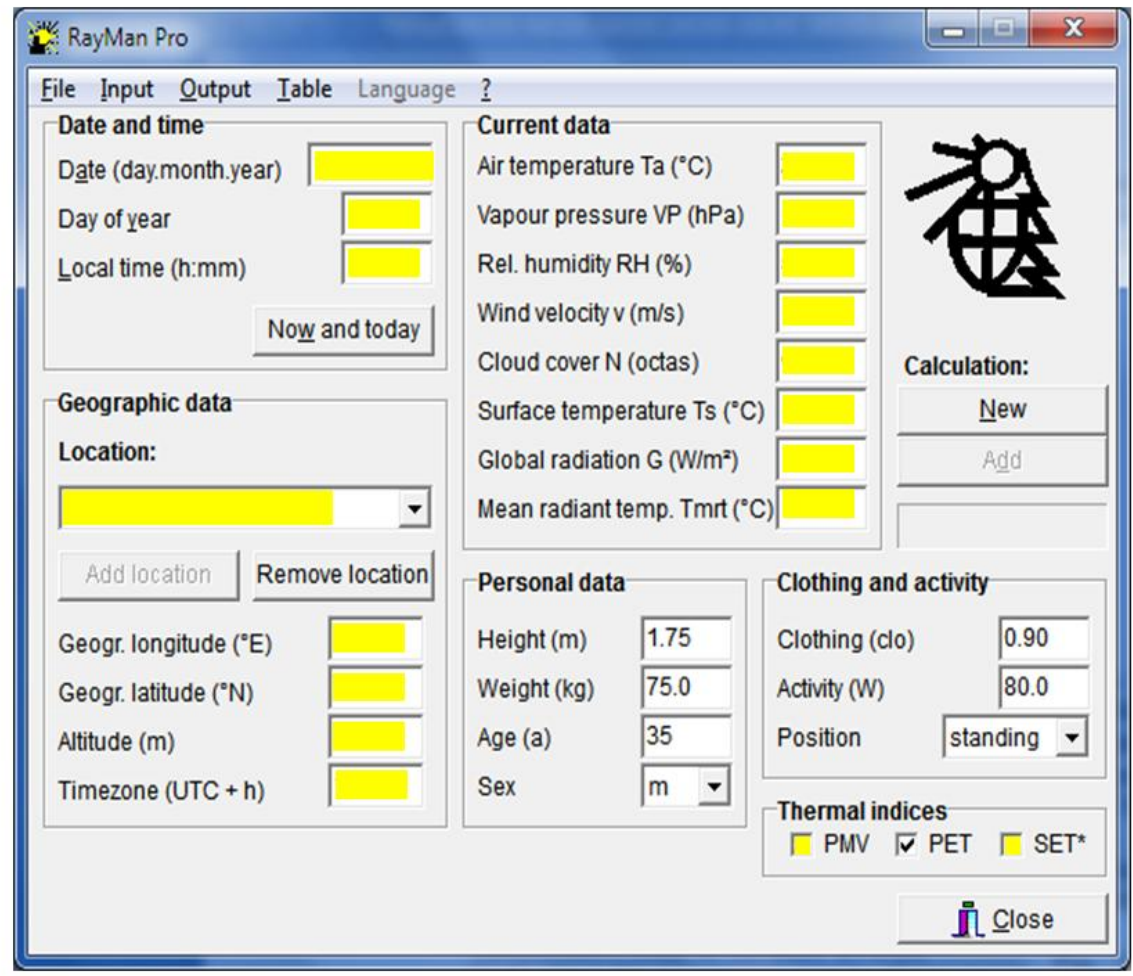

Figure 3: RayMan Pro and its controlling parameters. Source: http://www.mif.uni-freiburg.de/rayman/intro.htm 


\section{$121 \quad$ 2.4. Spatial Analytics}

122 Past meteorological data from the HKO are not of sufficient detail to account for the complex

123 terrain and dense urban morphology of Hong Kong. We propose a spatial approach that

124 integrates geographic information system (GIS) and remote sensing (RS) processing to derive the

125 needed parameters (Figure 4). It can be seen that the calculation of PET requires Ta, RH, WV,

126 Tmrt, and cloud cover. As HKO reports only the mean cloud cover percentage for each day, PET

127 will be computed by assuming the same cloud cover value for all locations. The Ta surface is

128 estimated from ASTER nighttime images [17] while the RH surface is generated by means of

129 spatial interpolation. WV near the ground level and Tmrt needs more computational efforts as

130 described below. The next section describes ways to estimate values of Ta, RH, WV, and Tmrt at

131 100m spatial resolution [see also 18] using spatial analysis methods. For illustrative purposes, we

132 will demonstrate a typical PET map for the warm season in 2008. 
Data

(specific time period)

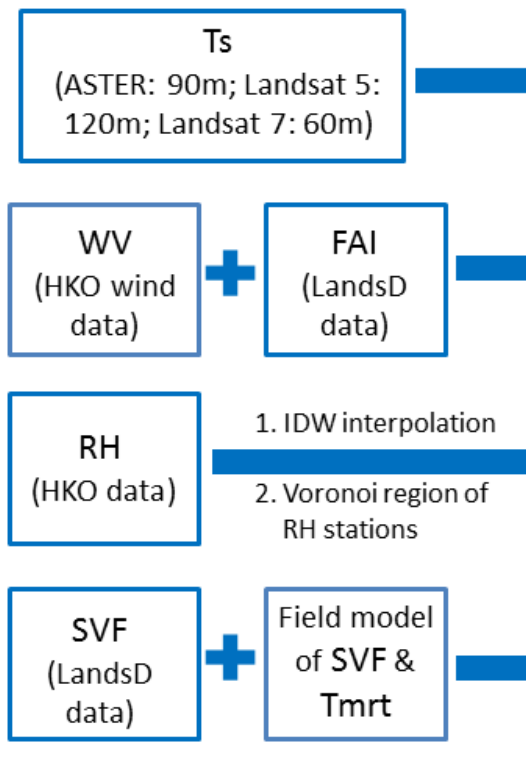

Cloud cover (HKO data - assume even over study area)
Either warm

or cool season

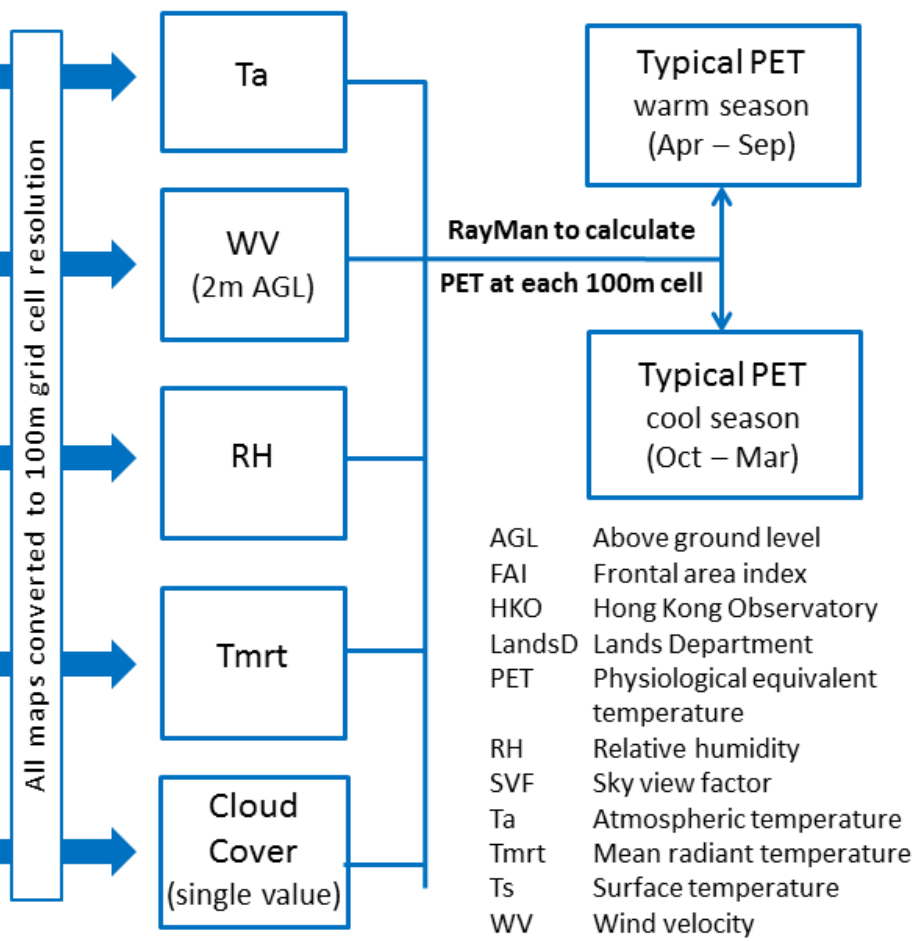

Figure 4: $\quad$ Spatial processing steps to deriving a map of thermal stress exposure

136 The Ta surface can be estimated from ASTER or LANDSAT images for a selected time period,

137 pending availability, and adjusted using the hourly Ta data from the HKO following the method

138 described in Nichol \& To [19]. Noting that daily meteorological data do vary spatially and

139 temporally, it is important to select a typical day in the summer/warm (April - September) or

140 winter/cool (October - March) months and compute the daily averages to represent typical

141 readings in different seasons [20,21]. Moreover, it is also difficult to get a satellite image that is

142 totally cloud free for each season [22, 23]. It may also be necessary to merge adjacent images

143 from different days to provide a complete coverage of the study area. 
145 RH values are monitored by weather monitoring stations managed by the HKO

146 (http://www.hko.gov.hk/cis/annex/hkwxstn_e.htm). The average RH values at each monitoring

147 station for a selected time period can be transformed into a continuous surface representation

148 through spatial interpolation. Given the interrupted landscape of Hong Kong comprising of

149 islands, the inverse distance weighted method is selected for the spatial interpolation [24].

150 Moreover, the extent of the interpolated surface is constrained within the Voronoi region [25] and

151 excluding the peripheral regions of Hong Kong. This constraint has little effect on our cohort

152 study (Figure 1) as the majority of subjects lie within the Voronoi region.

\section{2.4.3. Wind Velocity (WV)}

154 It has been noticed that low horizontal wind speeds are usually associated with high surface

155 roughness caused by a high density of built structures [26]. The WV surface at $2 \mathrm{~m}$ above the

156 ground level can be estimated by a map of Ground Coverage Ratio (GCR) derived from building

157 footprints. GCR is highly correlated with the WV ratio which is defined as the ratio of mean WV

158 at the pedestrian level to a reference height [27, 28]. It has been suggested as a good indicator for

159 the 3D roughness of an urban area, and can be further adjusted using the hourly wind data

160 available from the $\mathrm{HKO}$. The estimation can be done at 100m spatial resolution using building

161 data of a selected time period available from the Lands Department and applying the method

162 proposed by Wong \& Nichol [29].

\section{2.4.4. Mean Radiant Temperature (Tmrt)}

164 Tmrt, defined as the "uniform temperature of an imaginary enclosure in which the radiant heat 165 transfer from the human body equals the radiant heat transfer in the actual non-uniform 
enclosure" [30], is a complex variable which is affected by location, cloudiness and urban

167 morphology. Tmrt has been investigated and measured by field methods mostly in high-latitude

168 cities $[31,32]$. It has been asserted that the spatial difference of Tmrt, which is highly correlated

169 to urban morphology, can be estimated using the sky view factor (SVF) measured at the ground

170 level $[33,34]$. SVF is an indicator showing the relationship between built density, urban block

171 typology, and sky exposure at a location. Tmrt can be measured using a black-globe thermometer

172 to derive field measurements at representative locations over a specific time range [35]. These

173 Tmrt measurements are correlated against the corresponding SVF to yield a generalized model

174 calibrated to the local climate $[15,36]$ which can be used to derive the Tmrt surface.

\section{3. Results}

176 Figure 5 displays mapped surfaces of the above processes (with Kowloon enlarged to show

177 detail). Each step yields a map surface of parameters needed for the PET calculation. The Ta map

178 (Figure 5a) shows higher temperatures in urbanized Kowloon and built- up areas along the

179 northern coast of the Hong Kong Island. Cooler areas colored in blue correspond to locations of

180 country parks and open areas. This pattern agrees with the general understanding that natural

181 surfaces tend to be cooler than artificial surfaces. The RH map (Figure 5b) is mechanistically

182 looking because the surface was generated by automated means based on sparsely distributed

183 weather monitoring stations. Even though the map looks simplistic, the general pattern does

184 conform to our common understanding that vegetated areas have higher humidity compared to

185 built-up areas. As for the WV map (Figure 5c), it suffices to say that wind speeds are slower in

186 the densely urbanized parts of Kowloon and Hong Kong Island with many buildings. The Tmrt

187 map (Figure 5d) shows higher Tmrt in open areas without buildings. Studies have indicated that

188 Tmrt tends to be lowest in the densest urban environments due to shadowing [37]. 

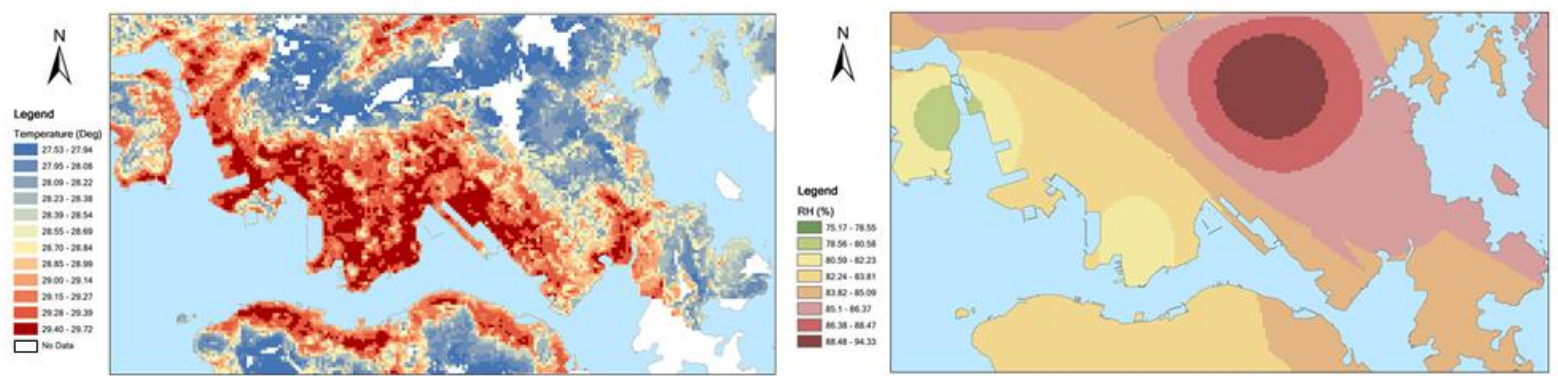

(a) Air temperature (Ta)

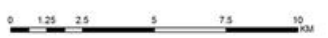

(b) Relative humidity $(\mathrm{RH})$
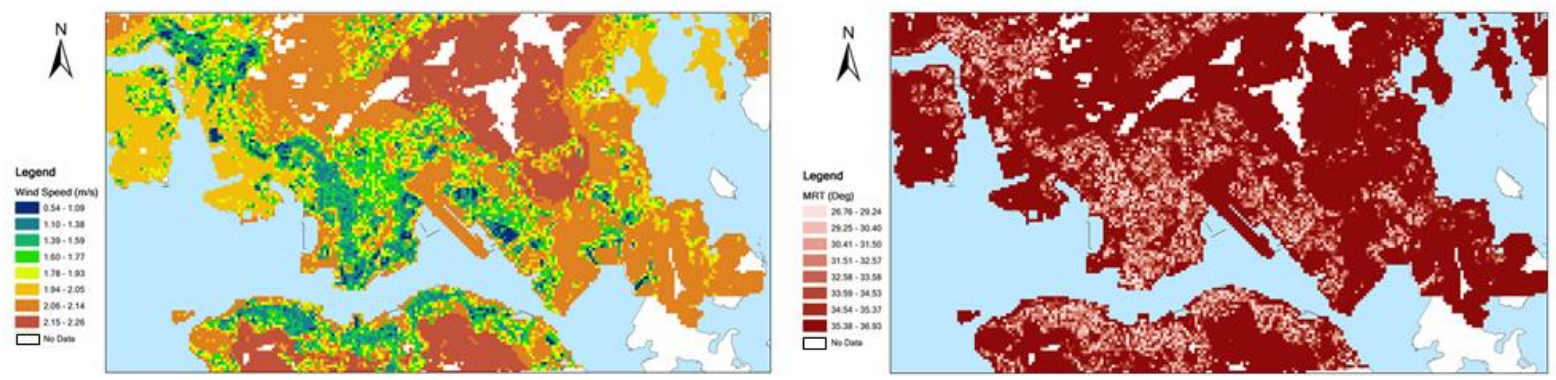

(c) Wind velocity (WV)

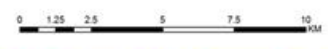

(d) Mean radiant temperature $(\mathrm{Tmrt}) \quad 0$

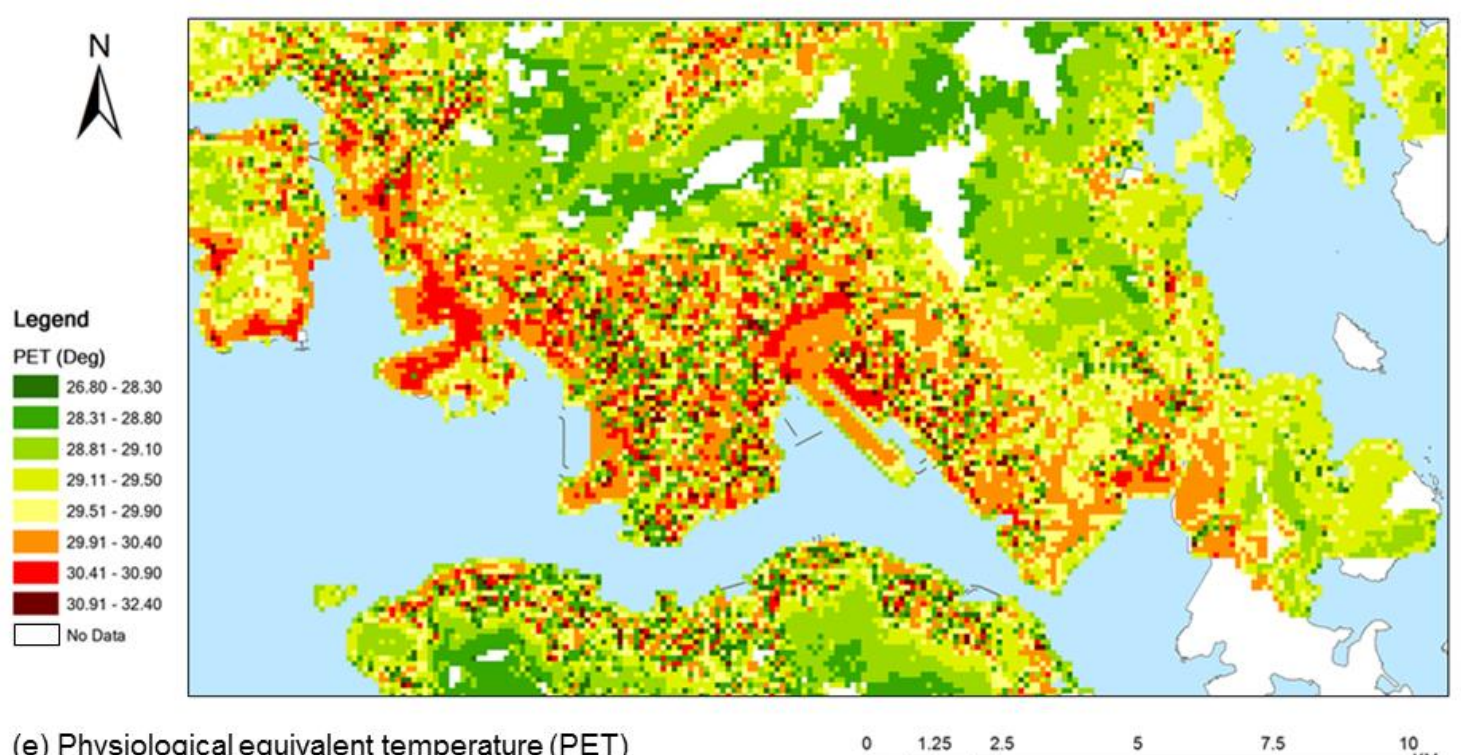

Figure 5: Results of interim maps and the final map of thermal stress exposure

190 The resultant PET map (Figure 5e) reveals an image that visually resembles the UC-AnMap

191 (Figure 2) although more blotchy in appearance. This may be due to more detailed variables

192 involved in the PET computation that amplifies differences between neighboring cells. Table 1

193 summarizes the relationship between the UC-AnMap and the resultant maps. Although not a 
194 strong positive relationship, the PET map is in general agreement with the UC-AnMap. The UC-

195 AnMap is correlated with all four parameters, showing a strong positive relationship with Ta and

196 negative relationships with the others (i.e., RH, WV, and Tmrt). Figure 6 is a plot of the PET

197 values against field measurements taken on 15 May 2008 from the UC-AnMap study [15]. The

198 plot suggests that the derived PET values, which were meant for the warm season in 2008,

199 corresponded rather well with those measured in the field at select locations in Tsuen Wan, a

200 small neighborhood in Hong Kong $\left(\mathrm{R}^{2}=0.5251\right)$. It is unfortunate that more extensive field

201 verification is not possible because other field measurements reported in the study were not for

202 the summer season [15].

203 Table 1 Correlation coefficients between UC-AnMap and PET-related variables

\begin{tabular}{|c|c|c|c|c|c|}
\hline Correlation & $\begin{array}{c}\text { Physiological equivalent } \\
\text { temperature } \\
\text { (PET) }\end{array}$ & $\begin{array}{c}\text { Air } \\
\text { temperature } \\
(\mathrm{Ta})\end{array}$ & $\begin{array}{c}\text { Relative } \\
\text { humidity } \\
(\mathrm{RH})\end{array}$ & $\begin{array}{c}\text { Wind } \\
\text { velocity } \\
(\mathrm{WV})\end{array}$ & $\begin{array}{c}\text { Mean radiant } \\
\text { temperature } \\
(\text { UC-AnMrt })\end{array}$ \\
$\begin{array}{c}\text { Urban Climate } \\
\text { Analysis Map }\end{array}$ & 0.23 & 0.70 & -0.29 & -0.90 & -0.67 \\
\hline
\end{tabular}

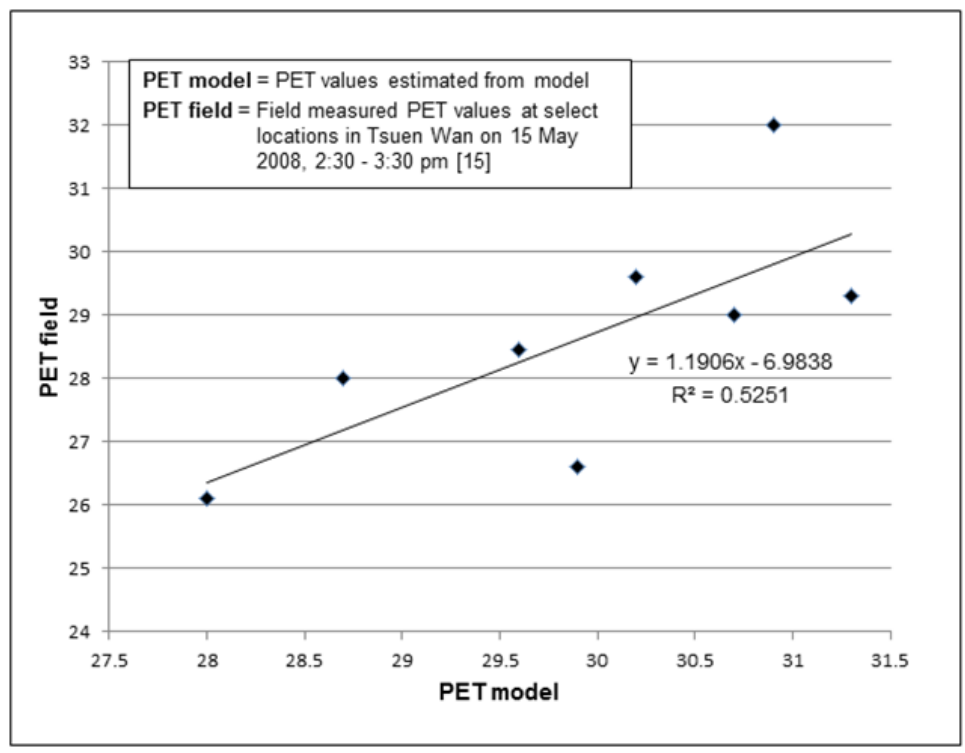


207 The fact that PET and UC-AnMap are correlated, even though not highly, may indicate that they

208 measure similar factors attributing to thermal stress. Results indicated in Table 1 above show that

209 three of four factors (i.e., WV, Ta, Tmrt) have very strong correlation with the UC-AnMap. The

210 three climatic analytical aspects for constructing the UC-AnMap included the followings: (i)

211 wind ventilation capturing local air circulation patterns, (ii) thermal environment focusing on

212 urban heat island effect, and (iii) areas of air pollution [15]. Although created based on

213 objectively and empirically collected data, the UC-AnMap is a synthetic outcome for planning

214 purposes because it also relies on expert and qualitative assessment of urban climatologists. In

215 this regard, the whole procedure and evaluation methods are not truly standardized as they

216 involved balancing and weighing many non-quantifiable aspects to arrive at a generalized view

217 of the urban thermal environment. All things being equal, our PET map can discriminate thermal

218 comfort conditions strictly from well-established mathematical procedures [5 - 8] without

219 subjective manipulation.

220 It is difficult to justify whether the resultant PET map (Figure 5e) is truly reflective of the real

221 thermal comfort conditions because the parameters were derivative from secondary procedures.

222 The estimation of Tmrt, for example, can be further improved by establishing a stronger

223 relationship between SVF and Tmrt through better choice of monitoring sites with specific

224 morphological features [38, 39]. Unfortunately, the estimation of RH could not be improved

225 given the limited and fixed number of meteorological stations in Hong Kong. It should also be

226 noted that the resultant PET map is not continuous because the Ta map (Figure 5a) was derived

227 from an ASTER image that was not totally cloud free. Here, the no-data cells did not affect

228 subsequent health impact analysis because no cohort subjects lived in these locations. Thus, it is 
229 important that cohort locations must be accounted for in the selection of satellite images.

231 This paper presents a methodology to construct high-resolution maps representing thermal stress

232 exposure in a city with complicated urban environment. It has demonstrated feasibility of the

233 approach that is repeatable because satellite imagery is a ubiquitous resource accessible to all

234 places on the Earth's surface and other data requirements can be satisfied easily. Provided that

235 there is sufficient weather monitoring stations to cover a selected study area, PET maps can be

236 created for different time periods based on local meteorological data on temperature, relative

237 humidity, wind, and cloud cover. The method not only accounts for changes in local

238 meteorological conditions but also the urban morphology as reflected through the building data.

239 The changing patterns of urban constructs, if captured in digital representation, will enable the

240 creation of PET surfaces of different time periods for comparative analysis.

241 A cohort study involving follow-up or longitudinal analysis is a research study for the detection

242 of association between within-person change and the thermal stress exposure in this case in

243 different geographic areas over a long period of time. It may not be possible to undertake certain

244 exposure measurements, especially for the baseline period in the past and subsequent time in the

245 future. This paper presents a methodology that makes use of available data and existing

246 techniques to derive the data needed for the analysis. With increasingly dense built-up cities,

247 planners and health practitioners are paying more attention to thermal comfort for urban

248 residents. The proposed method can also model robust estimates of human thermal comfort in the

249 future by considering consequences brought by global climate change and the more compact

250 urban form. 


\section{Acknowledgement}

252 This study was supported by the earmarked grant GRF 780512 of the Hong Kong Research

253 Grants Council. We thank the Hong Kong Government departments including the Department of

254 Health (Elderly Health Services) for the cohort data and the Hong Kong Observatory for

255 meteorological data. The geocoding of cohort locations was accomplished with support from the

256 Wellcome Trust. The authors are grateful for expert advice on the methodology provided by

257 Professor Lutz Katzschner, Institute for Environmental Meteorology, Kassel University, Kassel,

258 Germany. Wind velocity data at reference height was specially computed and provided by

259 courtesy of Professor Jimmy Fung, Institute for the Environment, Hong Kong University of

260 Science and Technology, Hong Kong. RayMan Pro software was provided by courtesy of

261 Professor Andreas Matzarakis, Universität Freiburg, Meteorologisches Institut, Hebelstr,

262 Germany. 


\section{Reference}

264 [1] Ryti NR, Guo Y, Jaakkola JJ. Global Association of Cold Spells and Adverse Health Effects: A Systematic Review and Meta-Analysis. Environ Health Persp 2015. doi:10.1289/ehp.1408104.

267 [2] Zhou X, Lian Z, Lan L. An individualized human thermoregulation model for Chinese adults. Build Environ 2013;70:257 - 265.

269 [3] Cheung CSC, Hart MA. Climate change and thermal comfort in Hong Kong. Int J $270 \quad$ Biometeorol 2014;58(2):137 - 148.

271 [4] Parsons K. Human thermal environments: the effects of hot, moderate, and cold 272 environments on human health, comfort, and performance. 3rd Edition. Boca Raton, FL: $273 \quad$ CRC Press. 2014.

274 [5] Höppe PR. Heat balance modelling. Experientia 1993;49(9):741 - 746.

275 [6] Matzarakis A, Rutz F, Mayer H. Modelling radiation fluxes in simple and complex 276 environments - basics of the RayMan model. Int J Biometeorol 2010;54:131 - 139.

277 [7] Matzarakis A, Rutz F, Mayer H. Modelling radiation fluxes in simple and complex environments - application of the RayMan model. Int J Biometeorol 2007;51(4):323 - 334.

279 [8] Höppe P. The physiological equivalent temperature - a universal index for the biometeorological assessment of the thermal environment. Int J Biometeorol 1999;43(2):71 -75 .

[9] Wang J, Brown DG, Hammerling D. Geostatistical inverse modeling for super-resolution mapping of continuous spatial processes, Remote Sens Environ 2013;139:205 - 215. 
284 [10] Basu R. High ambient temperature and mortality: a review of epidemiologic studies from 2001 to 2008. Environ Health 2009;8:40.

286

[11] Census and Statistics Department. Hong Kong: The Facts - Population. 2015. Available: http://www.gov.hk/en/about/abouthk/factsheets/docs/population.pdf [Accessed on 20 July 2015]

[12] Wong CM, Lai HK, Tsang H, Thach TQ, Thomas GN, Lam KB, Chan KP, Yang L, Lau AKH, Ayres JG, Lee SY, Chan WM, Hedley AJ, Lam TH. Satellite-Based Estimates of Long-Term Exposure to Fine Particles and Association with Mortality in Elderly Hong Kong Residents. Environ Health Persp 2015. doi: 10.1289/ehp1408264.

[13] Lam TH, Li ZB, Ho SY, Chan WM, Ho KS, Li MP, Leung GM. (2004). Smoking and depressive symptoms in Chinese elderly in Hong Kong. Acta Psychiat Scand 2004;110(3):195- 200 .

[14] Yim SHL, Fung JCH, Lau AKH, Kot SC. Developing a high-resolution wind map for a complex terrain with a coupled MM5/CALMET system, J Geophys Res-Atmos 2007 (1984 - 2012);112(D5): D05106. doi:10.1029/2006JD007752.

[15] Planning Department. Urban Climatic Map and Standards for Wind Environment Feasibility Study: Final Report. 2012. Available: http://www.pland.gov.hk/pland_en/p_study/prog_s/ucmapweb/ucmap_project/content/repo rts/final_report.pdf [Accessed on 4 Aug 2015]

[16] So HK, Nelson EA, Li AM, Wong EM, Lau JT, Guldan GS, Mak KH, Wang Y, Fok TF, Sung RY. Secular changes in height, weight and body mass index in Hong Kong Children. BMC Public Health 2008;8(1):320. 
[17] Fung WY, Lam KS, Nichol JE, Wong MS. Derivation of nighttime urban air temperatures using a satellite thermal image. J Appl Meteor Climatol 2009;48(4):863 - 872.

[18] Nichol JE, Wong MS. Spatial variability of air temperature and appropriate resolution for satellite-derived air temperature estimation. Int J Remote Sens 2008;29(24):7213 - 7223.

[19] Nichol JE, To PH. Temporal characteristics of thermal satellite images for urban heat stress and heat island mapping. ISPRS J Photogramm 2012;74:153 - 162.

[20] Ho HC, Knudby A, Sirovyak P, Xu Y, Hodul M, Henderson SB. Mapping maximum urban air temperature on hot summer days. Remote Sens Environ 2014;154:38 - 45.

314 [21] Song B, Park K. Validation of ASTER surface temperature data with in situ measurements to evaluate heat islands in complex urban areas. Adv Meteorol 2014;Article ID 620410.

[22] Grigsby SP, Hulley GC, Roberts DA, Scheele C, Ustin SL, Alsina MM. Improved surface temperature estimates with MASTER/AVIRIS sensor fusion, Remote Sens Environ $2015 ; 167: 53-63$.

[23] Huang F, Zhan W, Duan SB, Ju W, Quan J. A generic framework for modeling diurnal land surface temperatures with remotely sensed thermal observations under clear sky, Remote Sens Environ 2014;150:140 - 151.

322 [24] Lai PC, So FM, Chan KW. Spatial epidemiological approaches in disease mapping and analysis. Boca Raton, FL: CRC Press. 2009.

324 [25] Okabe A, Boots B, Sugihara K, Chiu SN. Spatial tessellations: concepts and applications of 325 Voronoi diagrams (Vol. 501). New York: John Wiley \& Sons. 2009. 
326 [26] Wong MS, Nichol JE, To PH, Wang J. A simple method for designation of urban ventilation 327 corridors and its application to urban heat island analysis. Build Environ 2010;45(8):1880 $328 \quad 1889$.

329 [27] Ng E, Yuan C, Chen L, Ren C, Fung JC. Improving the wind environment in high-density 330 cities by understanding urban morphology and surface roughness: a study in Hong Kong. $331 \quad$ Landscape Urban Plan 2011;101(1):59 - 74.

332 [28] Kubota T, Miura M, Tominaga Y, Mochida A. Wind tunnel tests on the relationship 333 between building density and pedestrian-level wind velocity: Development of guidelines 334 for realizing acceptable wind environment in residential neighborhoods. Build $335 \quad$ Environ 2008;43(10):1699- 1708.

336 [29] Wong MS, Nichol JE. Spatial variability of frontal area index and its relationship with 337 urban heat island intensity. Int J Remote Sens 2013;34(3):885 - 896.

338 [30] Wessel DJ. ASHRAE fundamentals handbook 2001 (SI edition). American Society of 339 Heating, Refrigerating, and Air-Conditioning Engineers, 31. 2001: chapter 8.

340 [31] Chen YC, Lin TP, Matzarakis A. Comparison of mean radiant temperature from field 341 experiment and modelling: a case study in Freiburg, Germany. Theor Appl Climatol $342 \quad 2014 ; 118(3): 535-551$.

343 [32] Lindberg F, Holmer B, Thorsson S, Rayner D. Characteristics of the mean radiant 344 temperature in high latitude cities - implications for sensitive climate planning applications. $345 \quad$ Int J Biometeorol 2014;58(5):613 - 627. 
346 [33] Scarano M, Sobrino JA. On the relationship between the sky view factor and the land 347 surface temperature derived by Landsat-8 images in Bari, Italy. Int J Remote Sens $348 \quad 2015 ; 16(19-20): 4820-4835$.

349 [34] Wang Y, Akbari H. Effect of Sky View Factor on Outdoor Temperature and Comfort in 350 Montreal. Environ Eng Sci 2014;31(6):272 - 287.

351 [35] Thorsson S, Lindberg F, Eliasson I, Holmer B. Different methods for estimating the mean 352 radiant temperature in an outdoor urban setting. Int J Climatol 2007;27(14):1983 - 1993.

353 [36] Tan CL, Wong NH, Jusuf SK. Outdoor mean radiant temperature estimation in the tropical $354 \quad$ urban environment. Build Environ 2013;64:118 - 129.

355 [37] Lau KKL, Ren C, Ho J, Ng E. Numerical modelling of mean radiant temperature in high356 density sub-tropical urban environment. Energ Buildings 2015. doi:10.1016/j.enbuild.2015.06.035.

358 [38] Klemm W, Heusinkveld BG, Lenzholzer S, Jacobs MH, Van Hove B. Psychological and 359 physical impact of urban green spaces on outdoor thermal comfort during summer time in 360 The Netherlands. Build Environ 2015;83:120 - 128.

361 [39] Krüger EL, Minella FO, Matzarakis A. Comparison of different methods of estimating the 362 363 mean radiant temperature in outdoor thermal comfort studies. Int J Biometeorol 2014;58(8):1727 - 1737 . 